\title{
A Monetary Policy Rule Based on Nominal and Inflation-Indexed Treasury Yields ${ }^{*}$
}

\author{
Brian Sack \\ Division of Monetary Affairs \\ Board of Governors of the Federal Reserve System \\ Washington, DC 20551
}

\begin{abstract}
The yields on nominal and inflation-indexed Treasury debt securities can be used to derive a proxy for the inflation expectations of financial market participants. This paper finds that one such measure has been an effective predictor of monetary policy decisions by the Federal Reserve since 1999. This finding suggests that the inflation compensation measure serves as a summary statistic for the factors that drive monetary policy decisions.
\end{abstract}

January 10,2002

\footnotetext{
* The opinions expressed are those of the author and do not necessarily reflect the views of the Board of Governors or other members of its staff. I thank Darrel Cohen, Refet Gürkaynak, and Bill Nelson for valuable suggestions. Comments are welcome to bsack@frb.gov.
} 


\section{Introduction}

Academics and financial market participants have made extensive efforts to describe the behavior of the Federal Reserve and other central banks using simple monetary policy rules. ${ }^{1}$ Under such rules, the policy instrument is assumed to respond only to a small number of macroeconomic variables, such as deviations of inflation from its target and of output from its potential level. But these simple specifications obscure the complexity of the actual policymaking process. Indeed, it is well known that central banks look at a wide range of variables and perform extensive analysis in formulating their policy decisions. ${ }^{2}$

One reason for the complexity of the policy process is that monetary policy decisions tend to be forward-looking. In fact, much of the effort of central banks is focused on forecasting the future course of the economy, so that policymakers can identify the emergence of inflationary pressures in advance and react in a preemptive manner. In this case, it might still be possible to describe monetary policy decisions using a simple policy rule, but the rule would presumably include the central bank's expectations for future inflation. ${ }^{3}$ Under such a rule, the complexity of the policymaking process shifts to the determination of the inflation forecast.

This observation raises the possibility that a measure of expected inflation, if it were available, might serve as an effective guide for monetary policy decisions. Unfortunately, the Federal Reserve does not release its own inflation forecast in a timely

\footnotetext{
${ }^{1}$ Taylor (1993) was among the first to investigate monetary policy rules. See Clarida, Gali, and Gertler (1999) for a broader review.

${ }^{2}$ See Bernanke and Boivin (2002) for a useful discussion of this issue and some empirical evidence on estimating monetary policy rules that incorporate information from an extensive number of data sources. ${ }^{3}$ Clarida, Gali, and Gertler (2000) were among the first to estimate a forward-looking monetary policy rule. Such rules are now common in the literature.
} 
manner. ${ }^{4}$ However, a simple measure of investors' expectations of future inflation can be derived from the Treasury securities market—namely, the difference between the yields on nominal Treasury securities and inflation-indexed securities, which is often referred to as the rate of inflation compensation.

This paper investigates whether one particular inflation compensation measure has been an effective predictor of monetary policy decisions in recent years. More specifically, the paper considers a forward rate of inflation compensation that serves as a proxy for expected inflation two to five years ahead. This measure is potentially quite powerful, in that it aggregates a vast amount of information into a single measure of a variable that is of primary interest to monetary policymakers - expected inflation.

Moreover, the analysis involved in forming an inflation forecast, no matter how complex, is simply embedded in this measure. Hence, this variable might serve as a useful summary statistic for the factors that drive monetary policy decisions.

\section{The Inflation Compensation Measure}

Treasury inflation-indexed securities (commonly referred to as TIPS) have coupon and principal payments that increase in line with the overall CPI. ${ }^{5}$ Because of this indexation, the quoted yield on a TIPS security represents (approximately) the real return that investors would receive by holding that security to maturity. The yield on a nominal Treasury security includes not only this real component, but also compensation to offset expected future inflation and the risks associated with that inflation. Thus, the

\footnotetext{
${ }^{4}$ The Federal Reserve staff's forecast for inflation is shown in the Greenbook, which is released with a five-year lag. Ranges for the forecasts of individual FOMC members are released twice a year in the Monetary Policy Report to the Congress.

${ }^{5}$ For details about the structure and pricing of inflation-indexed debt, along with a description of market activity to date, see Sack and Elsasser (2002).
} 
difference between nominal and inflation-indexed Treasury yields provides a measure of this second component—-the inflation compensation demanded by investors.

Inflation compensation is an imperfect measure of expected inflation because it can also be influenced by a number of other factors. The most obvious of these is the inflation risk premium. In addition, the measure might be influenced by differences in the liquidity of the securities and differences in their payment streams. ${ }^{6}$ To avoid distortions arising from liquidity differences, this paper calculates inflation compensation using off-the-run nominal Treasury securities, which are much closer to TIPS in terms of liquidity than are on-the-run nominal securities (see Sack and Elsasser (2002) for evidence). The other factors, including the inflation risk premium, are assumed to be stable enough to allow the inflation compensation measure to be an effective proxy for inflation expectations. Any distortions that remain in the inflation compensation measure would presumably limit its explanatory power.

\section{A Simple Monetary Policy Rule}

If the central bank is setting monetary policy based on concerns about future inflation, then inflation compensation may provide a useful guide for monetary policy decisions. Note that such a finding would not necessarily imply that policymakers are responding directly to the inflation compensation measure. It could simply reflect that the market-based measure of expected inflation is responding to the same information that is available to policymakers. In that sense, the inflation compensation measure

\footnotetext{
${ }^{6}$ This point is made by Sack (2000). That paper argues that TIPS should be compared to STRIPS or to offthe-run nominal securities in order to limit distortions arising from liquidity differences. It also discusses methods for matching payment streams, although this consideration is shown to have a fairly small effect.
} 
might provide a simple summary statistic for the extensive information and analysis that drive monetary policy decisions.

Given the inertia of inflation and the lag in the impact of monetary policy on the economy, policymakers are assumed to look through very near-term inflation and focus on the inflation outlook two to five years ahead. Accordingly, I construct a measure of "forward inflation compensation" for that horizon. That is, rather than looking at the difference between nominal and inflation-indexed Treasury yields, I consider the difference in the forward rates embedded in those yields. This measure reflects the compensation that investors demand for expected inflation from two to five years ahead.

The top panel of Figure 1 shows the measure of forward inflation compensation for the period from April 1999 to September 2002. ${ }^{7}$ The sample begins at this point because inflation compensation appears to have been significantly distorted in the fall of 1998 and early 1999 by the strong preference for liquidity at that time. ${ }^{8}$ The bottom panel shows the intended federal funds rate. As can be seen, the FOMC tightened the stance of monetary policy in 1999 and early 2000, a period when the forward inflation compensation rate was running in excess of 2 percent. Inflation compensation moved back down to 2 percent in mid-2000 and fell sharply below that level later in the year, while policy remained on hold. The FOMC then began to ease policy aggressively early in 2001 and continued to do so over the course of the year, as inflation compensation remained well below 2 percent. The FOMC stopped easing late in 2001, by which time

\footnotetext{
${ }^{7}$ Inflation compensation is measured between two outstanding TIPS - the July 2002 and the January 2007_ for the period up to January 2000. Since then, I use forward rates from two smoothed yield curves - one estimated from nominal off-the-run Treasury securities, and one estimated from TIPS. ${ }^{8}$ TIPS were less liquid than off-the-run nominal securities at that time, given that the program was still relatively new. See Sack and Elsasser (2002) for a discussion.
} 
inflation compensation moved up closer to 2 percent. Towards the end of the sample, the FOMC remained on hold even as inflation compensation again fell below 2 percent. ${ }^{9}$

Overall, it appears that the FOMC has tended to tighten (ease) policy when forward inflation compensation has exceeded (fallen below) 2 percent by a large enough margin. This observation suggests that monetary policy decisions over this period can be roughly characterized by a simple monetary policy rule of the following form:

$$
\Delta i_{t}=\beta \cdot\left(i c_{t}-\pi^{*}\right)
$$

where $i c_{t}$ is the forward inflation compensation rate, $\pi^{*}$ is the long-run level of inflation compensation, and $i_{t}$ is the nominal federal funds rate. ${ }^{10}$

The policy rule (1) can be motivated as follows. Although the current level of inflation will be influenced by the various shocks that have hit the economy, inflation should return to its target within some reasonable time horizon under an effective path for policy. If policy were on such a path, forward inflation compensation should be close to $\pi^{*}$, and the policy rule would indicate that the current setting of policy should not be changed. If the expected path of policy were instead seen as being too loose, forward inflation compensation would rise above $\pi^{*}$, in which case the policy rule would indicate that the FOMC should tighten. Conversely, the rule would indicate that the FOMC should ease if the policy path were viewed as too tight by this criterion.

Of course, the exact specification of the policy rule could have been written down in many forms other than the "difference rule" (1). This paper is not necessarily

\footnotetext{
${ }^{9}$ Data availability forces the sample to end in September 2002. But it is interesting to note that the FOMC eased policy by 50 basis points at the November 2002 FOMC meeting. So once again, the inflation compensation measure was an early indicator of monetary policy actions.

${ }^{10}$ Mehra (2001) also considers a monetary policy rule in which the FOMC reacts to the long-term bond rate, which he argues proxies for long-term inflation expectations.
} 
advocating this particular specification of the rule (as discussed more below). Instead, it is using this simple form of the policy rule to demonstrate the usefulness of the inflation compensation measure as a guide for policy decisions over this period. ${ }^{11}$

The policy rule (1) is estimated using observations taken at FOMC meetings or intermeeting policy changes from April 1999 to September 2002. ${ }^{12}$ Because the estimation is based on a very short sample ( 27 observations), the results should be viewed with caution. As shown in Table 1, the regression results indicate that the federal funds rate responds significantly to forward inflation compensation, as captured by the coefficient $\beta{ }^{13}$ The long-run level of inflation compensation, $\pi^{*}$, is estimated to be 2.02 and is also strongly significant. This parameter partly reflects the inflation objective of the central bank, although it will also be influenced by other factors driving a wedge between the average level of inflation compensation and the average level of inflation expectations, such as the inflation risk premium.

The estimated rule is very successful at describing policy actions over this period, with an $R^{2}$ statistic of 0.44 . This performance is impressive, considering that the rule contains only a single regressor. As a point of reference, a policy rule that determines quarterly changes in the federal funds rate based on inflation, the output gap, and the

\footnotetext{
${ }^{11}$ The policy rule considered is based on real-time data, given that market interest rates are not subject to revision. Hence, the rule addresses this important policy issue raised by Orphanides (2001) and others. ${ }^{12}$ The interest rate used is the intended federal funds rate. The inflation compensation measure is lagged one day so that the estimated coefficient is not affected by its endogenous response to the policy decision. To the extent that policy news also arrives on non-FOMC dates (for example, from speeches by FOMC members), this approach will not fully resolve the endogeneity problem.

${ }^{13}$ Clarida, Gali, and Gertler (2000) point out that a Taylor-type monetary policy rule can result in unstable macroeconomic dynamics when the response coefficient on inflation is less than 1 . Here, the finding that $\beta$ is less than 1 is not problematic, as the rule is specified in differences rather than levels.
} 
lagged interest rate has an $R^{2}$ statistic of 0.43 over the sample 1987Q1 to 2000Q1. ${ }^{14}$ Of course, rule (1) is benefiting from being estimated over a very short sample period.

Table 1: Estimates of Rule (1)

\begin{tabular}{ccc}
\hline \multicolumn{2}{c}{--- Coefficients --- } \\
$\beta$ & $\pi^{*}$ & $R^{2}$ \\
\hline 0.58 & 2.02 & 0.44 \\
$(3.81)$ & $(21.68)$ & \\
\hline & & \\
\hline T-statistics shown in parentheses are robust to serial correlation and heteroskedasticity.
\end{tabular}

Figure 2 shows the fit of the policy rule over the sample. As can be seen, during the tightening of policy in 1999 and 2000 (the points above the horizontal axis), the federal funds rate increased somewhat more than predicted by the estimated policy rule. Similarly, in 2001 (the points below the axis), policy eased more aggressively than expected under the rule. These observations would seem to indicate that policy actually has a stronger response coefficient to forward inflation compensation than indicated in the estimates from Table 1. However, the estimated coefficient is held down by two observations-December 2000 and May 2001— that seem to be outliers relative to the rest of the sample. ${ }^{15}$ These observations also stand out in Figure 3, which plots the time series of residuals from the regression (the difference between the actual and predicted changes in Figure 2). It is informative to look more closely at these two observations.

\footnotetext{
${ }^{14}$ This statistic is based on estimates from English, Nelson, and Sack (2002). See that paper for more details.

${ }^{15}$ If those two points are excluded from the estimation, the response coefficient $\beta$ increases to 0.78 (with a t-statistic of 8.11), and the long-run level of inflation compensation, $\pi^{*}$, edges down to 1.97 percent. The R-squared statistic jumps to 0.71 in that case.
} 
By the December 2000 FOMC meeting, inflation compensation had fallen to under 1.25 percent. In that sense, the yields on Treasury securities were sending a strong signal that the stance of monetary policy was too tight for the condition of the economy at that time. The estimated policy rule called for a 46 basis point easing, while the FOMC left the policy setting unchanged. Nevertheless, the FOMC at that meeting swung its balance of risks statement from being weighted towards inflationary pressures to being weighted towards economic weakness, and it eased the federal funds rate by 50 basis points in an intermeeting move just three weeks later. Thus, this episode highlights the value of having a market-based measure of inflation expectations to help inform policy decisions.

At the May 2001 FOMC meeting, inflation compensation had shot up sharply and briefly exceeded 2 percent, but the FOMC still cut the federal funds rate by 50 basis points. Looking back, inflation expectations might have been creeping up around that time, but it is somewhat implausible that they increased so extensively, which raises the possibility that the observed movements in Treasury yields were partly driven by other factors. That episode therefore highlights the shortcoming of using the inflation compensation measure as the single determinant of policy decisions.

\section{Potential Shortcomings}

The above results show that policy rule (1) is fairly effective at describing interest rate changes over this short period. Of course, a more important issue may be evaluating the effectiveness of such a rule in stabilizing output and inflation, which is not addressed 
in this paper. However, it is at least worth noting several issues regarding a rule of the form (1).

First, as described above, inflation compensation does not precisely measure inflation expectations. Variation in other factors influence the inflation compensation measure, such as inflation risk, liquidity concerns, and the supply of Treasury securities, would limit the performance of the monetary policy rule (1). This consideration argues in favor of using inflation compensation in conjunction with a broader set of statistics and analysis in deriving a forecast of future inflation and future policy movements.

Second, the horizon for the inflation compensation measure used in the policy rule (two to five years ahead) was chosen in part based on the available maturities of outstanding TIPS and may not be appropriate. Determining the optimal horizon for a forward-looking rule is a difficult issue that requires more extensive analysis (see Batini and Nelson (2001), for example). Moreover, there are a number of important issues to be considered in evaluating the performance of such rules, including whether responding to private-sector expectations induces instability (see Bernanke and Woodford (1997)) and whether forward-looking rules are robust to model uncertainty (see Levin, Wieland, and Williams (2003)).

Third, the monetary policy rule (1) could take a variety of forms. I chose to specify the rule in terms of first differences in the federal funds rate, but the rule could also have been specified in terms of levels. ${ }^{16}$ The difference rule has a reasonable interpretation of making adjustments along some optimal response based on the views of market participants. However, as with the previous point, more extensive analysis is

\footnotetext{
${ }^{16}$ As indicated above, the choice of a difference rule is empirically motivated. If the rule is estimated in levels, the coefficient on the lagged policy rate is not statistically different from 1.
} 
required to determine the benefits of specifying the rule in this manner (see, among others, Levin, Wieland, and Williams (1999)).

\section{Conclusions}

This paper highlights the valuable information contained in inflation compensation measures for predicting and potentially guiding monetary policy decisions. The results demonstrate that a simple policy rule in which the federal funds rate reacts only to the forward rate of inflation compensation performs well at describing the behavior of the FOMC since 1999. In particular, the FOMC has tended to tighten when the inflation compensation measure has risen sufficiently above 2 percent, and to ease when it has fallen sufficiently below 2 percent. Of course, this is a very short sample that only includes two policy "cycles" - the 1999/2000 tightening and the 2001 easing - and so this conclusion should be taken with caution. Nevertheless, the estimated policy rule fits well enough over this period to be of some interest at this early stage.

Not only are inflation compensation measures useful for describing past policy actions, but they could be quite valuable to monetary policymakers for formulating realtime policy decisions. After all, these measures incorporate vast amounts of information and summarize the views of a wide set of investors. In addition, unlike surveys of inflation expectations, these measures are available to policymakers on a timely and continuous basis. Thus, policymakers could use inflation compensation measures to help formulate their views on the outlook for inflation, or at least as a check of whether their views are consistent with those of financial market participants. As noted above, inflation compensation measures are likely to be distorted at times by factors unrelated to 
inflation expectations. However, it appears that those distortions have been small enough over the past several years that they have not detracted significantly from the usefulness of inflation compensation as a guide for monetary policy decisions.

\section{References}

Batini, Nicoletta and Edward Nelson (2001), "Optimal Horizons for Inflation Targeting," Journal of Economic Dynamics and Control 25, 891-910.

Bernanke, Ben S. amd Jean Boivin (2002), "Monetary Policy in a Data-Rich

Environment," forthcoming, Journal of Monetary Economics.

Bernanke, Ben S. and Michael Woodford (1997), "Inflation Forecasts and Monetary Policy," Journal of Money, Credit, and Banking 29, 653-684.

Clarida, Richard, Jordi Gali, and Mark Gertler (1999), “The Science of Monetary Policy: A New Keynesian Perspective," Journal of Economic Literature 37, 1661-1707.

Clarida, Richard, Jordi Gali, and Mark Gertler (2000), "Monetary Policy Rules and Macroeconomic Stability: Evidence and Some Theory," Quarterly Journal of Economics $115,147-180$.

English, William B., William R. Nelson, and Brian P. Sack (2002), “Interpreting the Significance of the Lagged Interest Rate in Estimated Monetary Policy Rules," Finance and Economics Discussion Series Working Paper No. 2002-24, Board of Governors of the Federal Reserve System.

Levin, Andrew, Volker Wieland, and John Williams (1999), "The Robustness of Simple Monetary Policy Rules under Model Uncertainty," in Monetary Policy Rules (J. B. Taylor, ed.), Chicago: NBER and Chicago Press. 
Levin, Andrew, Volker Wieland, and John Williams (2003), "The Performance of Forecast-Based Policy Rules under Model Uncertainty," forthcoming, American Economic Review.

Mehra, Yash P. (2001), “The Bond Rate and Estimated Monetary Policy Rules," Journal of Economics and Business 53, 345-358.

Orphanides, Anthanasios (2001), "Monetary Policy Rules Based on Real-Time Data," American Economic Review 91, 964-985.

Sack, Brian (2000), "Deriving Inflation Expectations from Nominal and InflationIndexed Treasury Yields," Journal of Fixed Income 10, 1-12.

Sack, Brian and Robert Elsasser (2002), "Treasury Inflation-Indexed Debt: A Review of the U.S. Experience," Finance and Economics Discussion Series Working Paper No. 2002-32, Board of Governors of the Federal Reserve System.

Taylor, John B. (1993), "Discretion versus Policy Rules in Practice," Carnegie Rochester Conference Series on Public Policy 39, 195-214. 
Inflation Compensation, Two to Five Years Ahead

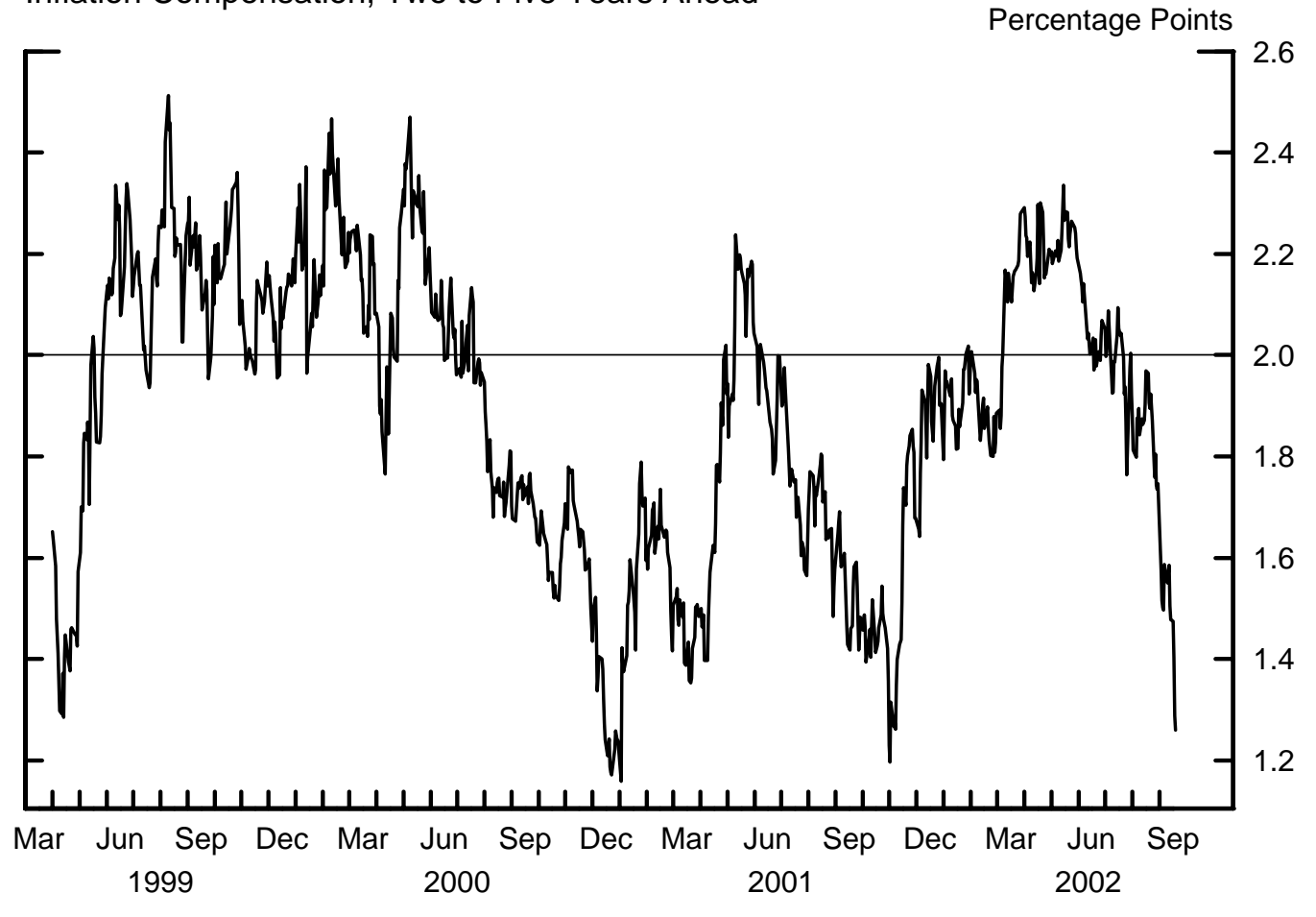

Intended Federal Funds Rate

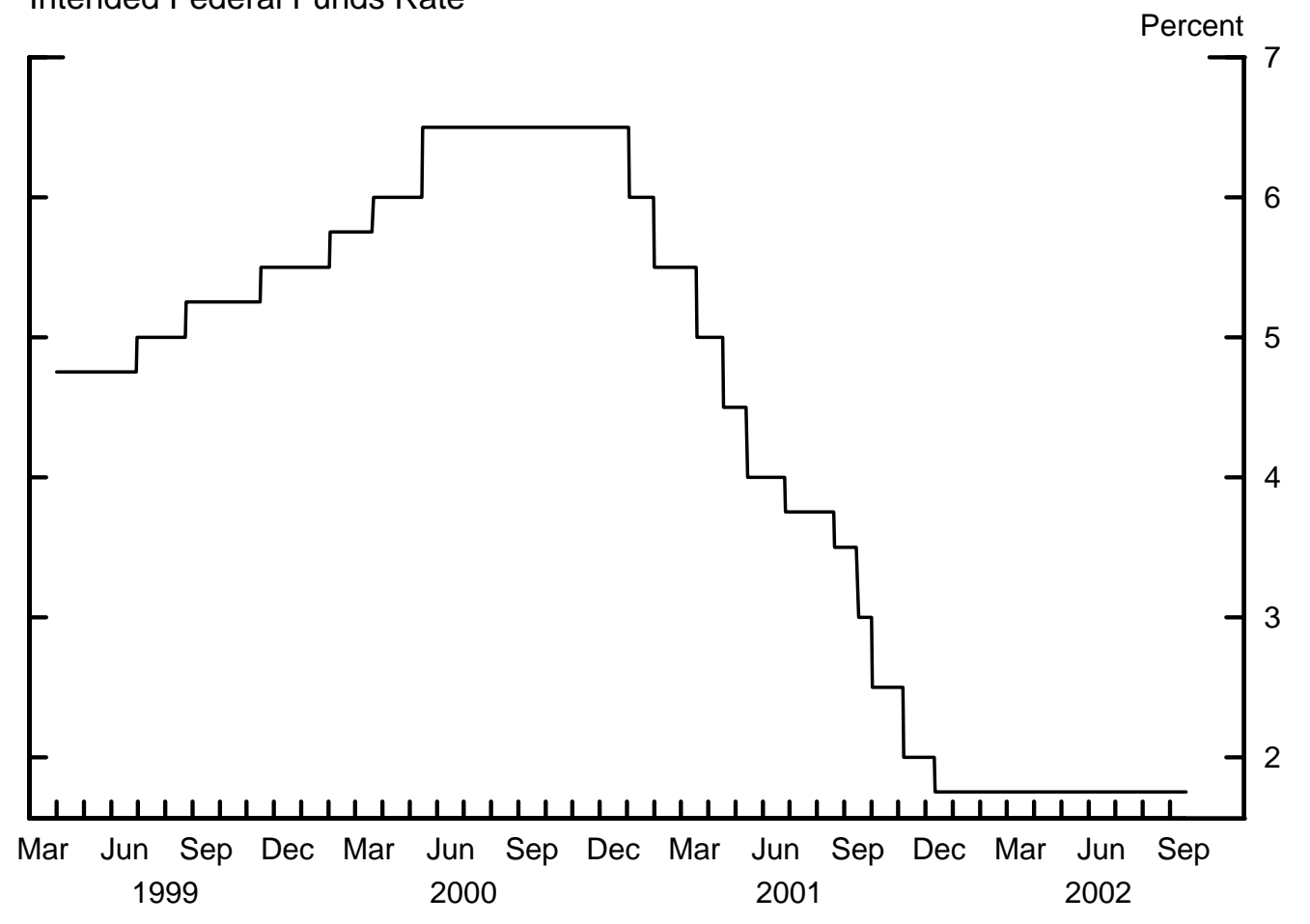


Figure 2

Empirical Fit of Policy Rule (1)

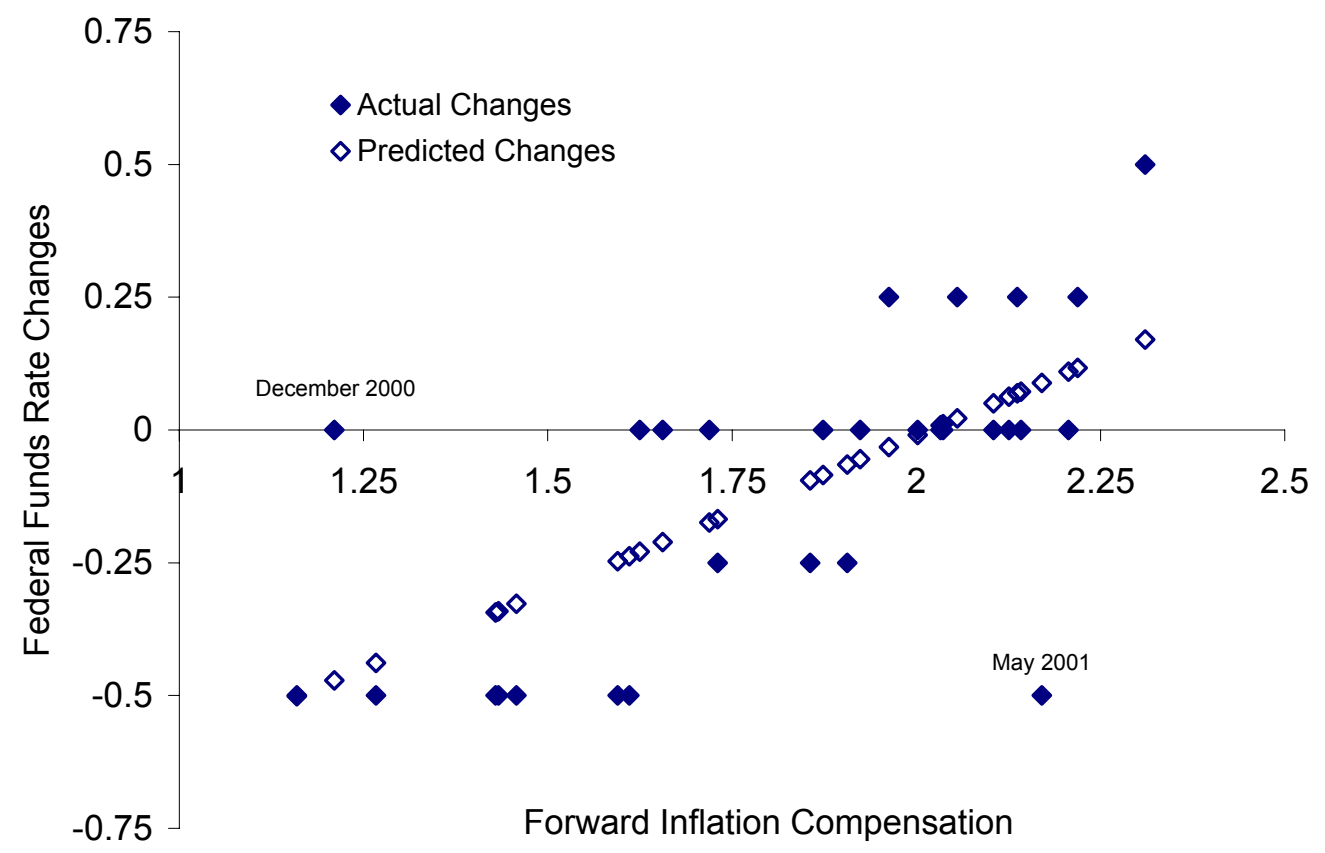


Figure 3

Errors from Monetary Policy Rule (1)

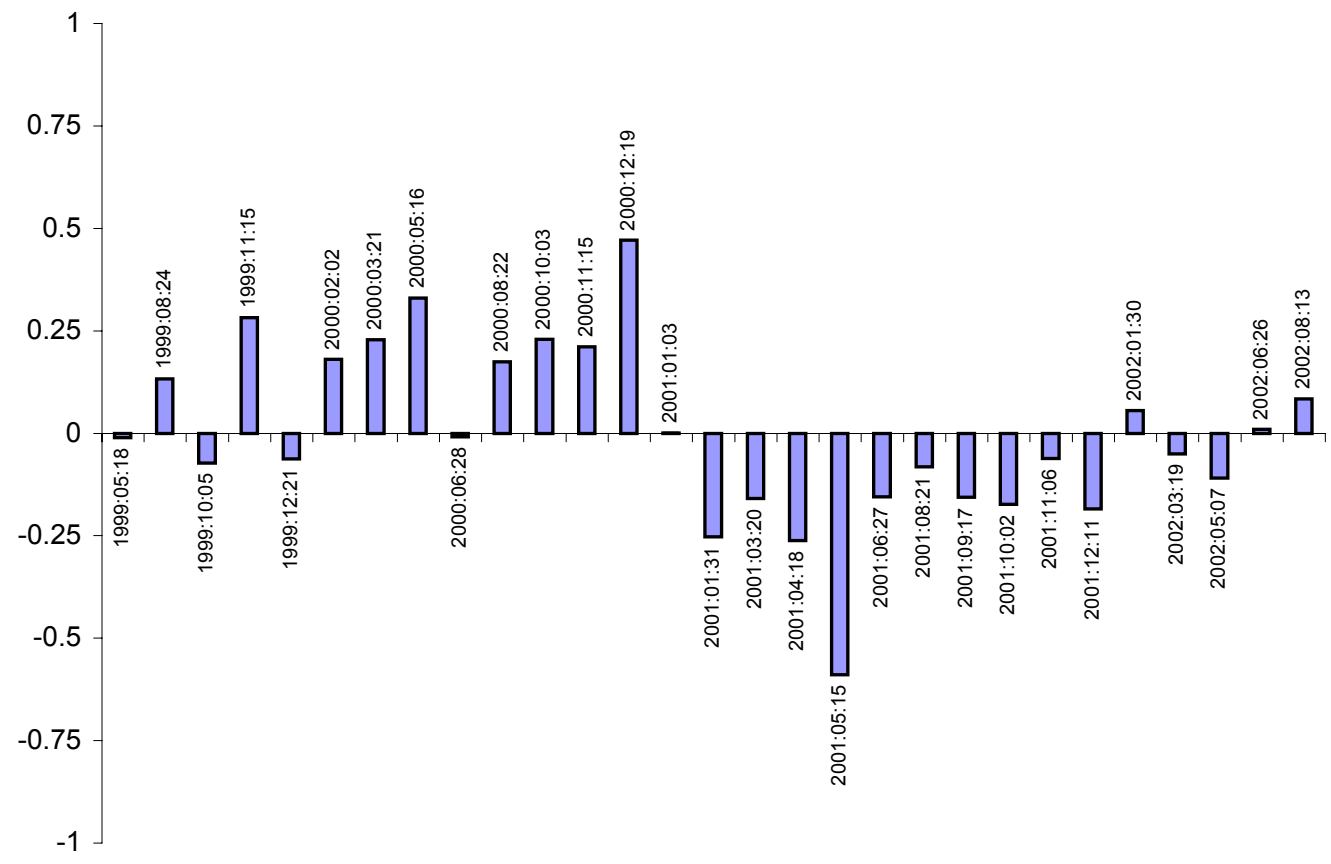

